\title{
Application of transanal irrigation for patients with spinal cord injury in South Korea: a 6-month follow-up study
}

\author{
HR Kim ${ }^{1}$, BS Lee ${ }^{2}$, JE Lee ${ }^{3}$ and HI Shin ${ }^{1}$
}

Study design: A 6-month follow-up study.

Objectives: To investigate the outcome of transanal irrigation (TAI) in patients with spinal cord injury (SCI) and to identify factors significantly related to clinical success.

Setting: Survey for community-dwelling patients with $\mathrm{SCl}$ in South Korea.

Methods: Between December 2010 and March 2012, TAl was initiated with 52 patients (41 men; age: $44.5 \pm 11.0$ years) with neurogenic bowel dysfunction (NBD). At 1, 3 and 6 months after initiation, a telephone interview was conducted. Data were collected on patient-specific bowel management and TAI performance as a new procedure.

Results: Only 18 patients (34\%) used TAI for at least 6 months, which was a lower compliance rate than similar studies in some European countries. Relative to the compliant group, the noncompliant group contained a higher proportion of tetraplegia than paraplegia $(P=0.031)$, and a higher proportion dependent on physical help $(P=0.034)$. In all, 33 of the 52 patients $(63.5 \%)$ complained of practical problems with the TAI procedure such as expulsion of the rectal catheter. Fifteen patients (28.8\%) presented with adverse effects. The incidence of practical problems or adverse effects did not alter the frequency of patient-reported successful outcome.

Conclusion: Korean participants showed a relatively lower compliance rate with TAI. We conclude that TAI, combined with adequate patient instruction and physical assistance, has potential as a management tool for NBD in Korea.

Spinal Cord (2013) 51, 389-394; doi:10.1038/sc.2012.171; published online 15 January 2013

Keywords: spinal cord injury; neurogenic bowel; transanal irrigation; defecation; assistance

\section{INTRODUCTION}

Most spinal cord injury patients (SCIPs) suffer from neurogenic bowel dysfunction (NBD). ${ }^{1-3}$ Although this is not life threatening, it reduces quality of life (QoL) and restricts social activities. ${ }^{4}$ In total, $39 \%$ of SCIPs report that bowel dysfunction negatively impacts their QoL, sometimes profoundly, and 30\% regard colorectal dysfunction as worse than bladder or sexual dysfunction. ${ }^{5}$

Recent studies have shown that transanal irrigation (TAI) is an efficient method for improving bowel function and QoL in SCIPs. ${ }^{1,2,4,6}$ In addition, TAI is more cost-effective than conservative bowel management. ${ }^{7}$

The majority of research on TAI has been conducted in European countries ${ }^{1-4,6-8}$ and there have been very few studies on this topic in Asia. In South Korea, TAI is rare in clinical practice and has engendered few research studies. In one study of bowel dysfunction in Korea, it was found that $2.9 \%$ of respondents used warm water TAI to stimulate defecation by pouring 500 to $1000 \mathrm{ml}$ of warm water into the rectum, using a simple enema set. ${ }^{9}$ In these cases, the enema procedure was not taught by medical personnel but by peer SCIPs, and the commercially available TAI devices were not used. This might be because TAI procedures are not reimbursed by the national health insurance system in South Korea. Moreover, a TAI device is too expensive (about USD 250) for many SCIPs and the frequency of medical consultation for bowel dysfunction is relatively low. ${ }^{10}$

It appears that for Korean SCIPs, bowel care habits are very individualized ${ }^{10}$ and the choice of method is markedly influenced by the patient's sociocultural environment. ${ }^{11}$ Moreover, as health-care systems vary widely between countries, this can be expected to influence the bowel care habits of SCIPs.

The aim of this study was to investigate the outcomes of TAI use by SCIPs in Korea with the objective of identifying factors significantly related to patient-reported success.

\section{MATERIALS AND METHODS}

From December 2010 to March 2012, patients were recruited from one academic tertiary care hospital and two rehabilitation hospitals. Inclusion criteria were: (1) at least 18 years old; and (2) suffered a spinal cord injury (SCI) at least 6 months before enrollment and presented with NBD and unsatisfactory bowel management. For this study, NBD with unsatisfactory bowel management was defined as: (1) taking at least half an hour over attempts to defecate; or (2) had fecal incontinence; or (3) experienced symptoms of autonomic dysreflexia related to defecation., ${ }^{4,6}$ Exclusion criteria were: (1) a history of depression or related disorder; (2) alcohol abuse; (3) a history of colon disease unrelated to SCI (such as inflammatory bowel disease or bowel obstruction); (4) a history of major abdominal surgery;

\footnotetext{
${ }^{1}$ Department of Rehabilitation Medicine, Seoul National University Bundang Hospital, Seoul National University College of Medicine, Seongnam-si, Gyeonggi-do, Republic of Korea; ${ }^{2}$ Department of Rehabilitation Medicine, National Rehabilitation Center, Seoul, Republic of Korea and ${ }^{3}$ Department of Occupational Therapy, Yeeun Hospital, Bucheon-si, Gyeonggi-do, Republic of Korea

Correspondence: Professor HI Shin, Department of Rehabilitation Medicine, Seoul National University Bundang Hospital, 82, Gumi-ro 173 Beon-gil, Bundang-gu, Seongnam-si, Gyeonggi-do 463-707, Republic of Korea.

E-mail: hyungik1@snu.ac.kr
}

Received 25 September 2012; revised 21 November 2012; accepted 28 November 2012; published online 15 January 2013 
(5) a history of central nerve system disease unrelated to SCI; or (6) previous treatment with TAI.

In all, 57 SCIPs expressed the intention to participate in the study and 52 were finally accepted. Of the five rejected, three never performed TAI, one was hospitalized for pyelonephritis unrelated to TAI and one did not participate in the telephone interview (Figure 1).

\section{Study design}

Eligible SCIPs were admitted to the study after completion of a written informed consent, records of personal information and medical history included details of intestinal function at initial assessment. Participants and caregivers were instructed by a trained investigator in the outpatient clinic on the use of the TAI device using a rectum model. Participants were encouraged to seek advice by telephone, especially at the initiation of training. Furthermore, an investigator blinded to the study design performed a frequent telephone interview with the participants and routinely referred any treatmentrelated questions to the responsible researcher.

The research questionnaire was conducted by telephone at 1,3 and 6 months after entry. Participants who expressed a wish to stop treatment were withdrawn from the study (Figure 1).

\section{Transanal irrigation}

The Peristeen Anal Irrigation System (Coloplast A/S, Humlebæk, Denmark) was used for bowel management. The catheter is inserted into the rectum and the balloon inflated to hold the catheter in place while warm tap water is slowly administered. Subsequently, the balloon is deflated and the catheter removed. The initial treatments were with $500 \mathrm{ml}$ of water and this was could be increased by $100 \mathrm{ml} \mathrm{day}^{-1}$ to a maximum of $1000 \mathrm{ml}$. The volume of water used and the frequency of TAI were adapted to individual patient needs during the first several weeks of treatment.

\section{Questionnaire}

The survey included questions on age, sex and bowel care habits, as well as information on the date, type and cause of SCI. Data on the frequency of defecation, awareness of the need to defecate, main defecation method and the average time required for defecation referred to the international bowel function basic SCI data set. ${ }^{12}$ The average time required for defecation was assessed on a five-step scale (1: $\leqslant 10 \mathrm{~min}, 2: 11-20 \mathrm{~min}, 3: 21-30 \mathrm{~min}, 4: 31-$ $60 \mathrm{~min}$ and $5: \geqslant 61 \mathrm{~min}$ ). The frequency of defecation was assessed on a six-step scale $(1: \geqslant 3$ times per day, $2: 2$ times per day, $3: 1$ time per day, $4:>2$ times per week, 5: 2 times per week and 6: 1 time per week). Data on intestinal symptoms and the need for assistance during bowel management were also collected. Self-reported impact of bowel dysfunction on QoL was measured by qualifier scales used in the International Classification of Function, Disability and Health (0: no problem, 1: mild, 2: moderate, 3: severe and 4: complete).$^{13}$

Patient satisfaction and impact on QoL were assessed on numeric rating scales: satisfaction of TAI (range, 0-10, with 10 representing perfect satisfaction), impact of TAI on QoL (range, $0-10$, with 10 representing strong positive impact). Need for assistance during TAI, practical problems, adverse effects and any other reason for withdrawal were also recorded.

\section{Statistical analysis}

Statistical analysis was performed to examine the significance of factors predicting successful use of TAI. Chi-squared and Mann-Whitney tests were used for comparisons between patients who complied with TAI use and those who ceased TAI use during the study period. For the compliant group, the Wilcoxon signedranks test was used to analyze the differences between assessment parameters at entry and at 6 months. Significance was set at a $P$-value $<0.05$. All analyses were computed using SPSS 20.0 (IBM Corp., Armonk, NY, USA).

\section{Statement of ethics}

We certify that all applicable institutional and governmental regulations concerning the ethical use of human volunteers were followed during the course of this research (IRB no. E-1011-056-001).

\section{RESULTS}

The mean age of the 52 enrollees at application was $44.5 \pm 11.0$ years and $41(78.8 \%)$ patients were men. Table 1 shows details of patient

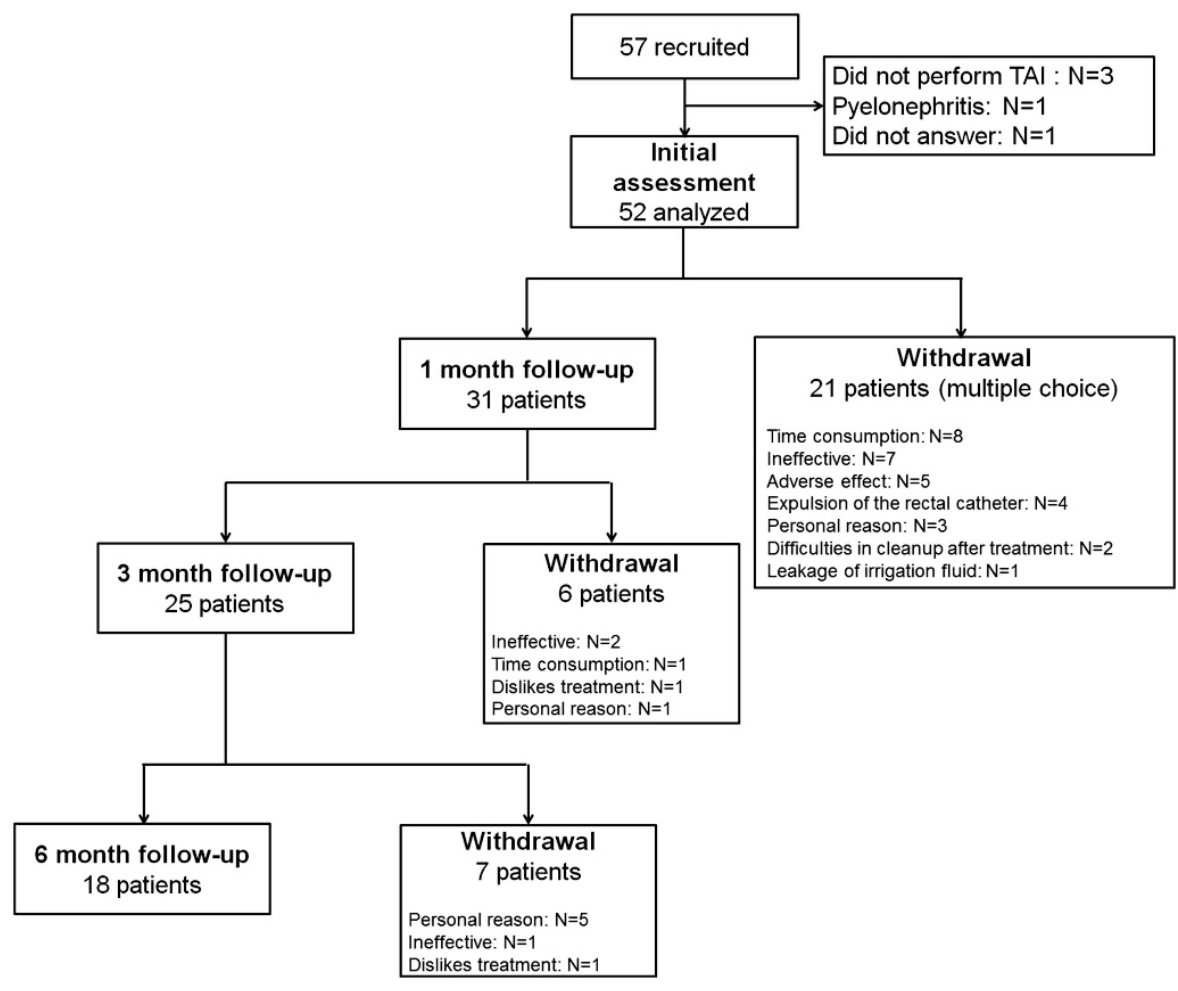

Figure 1 Trial profile. 
Table 1 Patient demographics at initial visit $(n=52)$

\begin{tabular}{lc}
\hline & Number (\%) of patients \\
\hline Age, mean \pm s.d. (median, range) (years) & $44.5 \pm 11.0$ \\
& $(45.5,18-65)$ \\
Sex (male/female) & $41 / 11$ \\
Time since injury, mean \pm s.d. (median, range) (months) & $92.9 \pm 118.4$ \\
& $(39.6,6.0-510.6)$ \\
Type of injury & \\
Tetraplegia & \\
Paraplegia & $28(53.8 \%)$ \\
& $24(46.2 \%)$ \\
Cause of injury & \\
Trauma & $41(78.8 \%)$ \\
Non-trauma & $11(21.2 \%)$ \\
Congenital abnormality & 4 \\
Myelitis & 3 \\
Surgery & 2 \\
Ossification of posterior longitudinal ligament & 1 \\
Cauda equina syndrome & 1 \\
\hline
\end{tabular}

baseline demographic data. Bowel care habits at enrollment are listed in Table 2.

\section{Final outcome}

Among the 52 patients, compliance with the use of TAI at 1, 3 and 6 months was $31(59.6 \%), 25(48.1 \%)$ and 18 (34.6\%) patients, respectively (Figure 1).

\section{Comparing the compliant group with the noncompliant group}

Comparing the 18 compliant and 34 noncompliant patients at 6 months, the noncompliant group contained a higher proportion of tetraplegia than paraplegia $\left(\chi^{2}\right.$ test; $\left.\chi^{2}(1)=4.661 ; P=0.031\right)$ and a higher need for assistance during bowel management (Fisher's exact test; $P=0.034)$. After 6 months, 6 out of $28(21.4 \%)$ tetraplegic patients and 12 out of $24(50 \%)$ paraplegic patients were using TAI. There was no significant difference between these two groups in parameters such as age, sex, time since injury, cause of injury, average time required for defecation, frequency of defecation, constipation and incontinence. The noncompliant group also showed a borderline higher need for assistance during the TAI procedure (Fisher's exact test; $P=0.076$ ); however, there was no difference between the groups in the incidence of practical problems or adverse effects (Table 3 ).

\section{Effects of TAI on bowel management at 6 months after initiation of} procedure

The performance of TAI in the compliant group is listed in Table 4. Relative to baseline measurements, this group showed a decreased defecation time and an increased QoL (Wilcoxon signed-ranks test; $P=0.005, P=0.003$, respectively; Table 5). The 11 patients who were dependent on physical assistance for defecation at enrollment remained dependent on physical assistance for TAI after 6 months. One patient who was independent for bowel management required assistance for the TAI procedure.

Feasibility of TAI for extended periods of bowel care

Of the 52 enrollees, two individuals spent $>12 \mathrm{~h}$ of the day on defecation. Typically, they used full daytime on bowel care. These
Table 2 Characteristics of bowel care habits at the initial visit $(n=52)$

\begin{tabular}{|c|c|}
\hline & Number (\%) of patients \\
\hline \multicolumn{2}{|l|}{ Intestinal symptom (multiple choice) } \\
\hline Constipation & 28 \\
\hline Pain or discomfort during defecation & 20 \\
\hline Hemorrhoid or anal bleeding & 18 \\
\hline Incontinence & 15 \\
\hline Autonomic dysreflexia related to defecation & 9 \\
\hline \multicolumn{2}{|l|}{ Average time required for defecation } \\
\hline$\leqslant 10 \min$ & $0(0 \%)$ \\
\hline $11-20 \mathrm{~min}$ & $1(1.9 \%)$ \\
\hline $21-30 \mathrm{~min}$ & $2(3.8 \%)$ \\
\hline $31-60 \mathrm{~min}$ & $10(19.2 \%)$ \\
\hline$\geqslant 61 \mathrm{~min}$ & $39(75.0 \%)$ \\
\hline \multicolumn{2}{|l|}{ Frequency of defecation } \\
\hline Three times or more per day & $1(1.9 \%)$ \\
\hline Twice daily & $1(1.9 \%)$ \\
\hline Once daily & $5(9.6 \%)$ \\
\hline Not daily but more than twice every week & $24(46.2 \%)$ \\
\hline Twice every week & $15(28.8 \%)$ \\
\hline Once every week & $6(11.5 \%)$ \\
\hline \multicolumn{2}{|l|}{ Awareness of the need to defecate } \\
\hline Normal & $9(17.3 \%)$ \\
\hline Indirect & $13(25.0 \%)$ \\
\hline None & $26(50.0 \%)$ \\
\hline Unknown & $4(7.7 \%)$ \\
\hline \multicolumn{2}{|l|}{ Main defecation method (multiple choice) } \\
\hline Suppositories & 37 \\
\hline Digital anorectal stimulation & 10 \\
\hline Digital evacuation & 6 \\
\hline Other method & 5 \\
\hline Straining/bearing down to empty & 3 \\
\hline Mini enema (Clysma $\leqslant 150 \mathrm{ml}$ ) & 2 \\
\hline Normal defecation & 2 \\
\hline \multicolumn{2}{|l|}{ Oral laxatives (multiple choice) } \\
\hline Yes & 39 \\
\hline Osmotic or bulking laxatives (tablets or granulates) & 34 \\
\hline Osmotic laxatives (drops) & 4 \\
\hline Irritant laxatives (tablets) & 2 \\
\hline Prokinetics & 2 \\
\hline Herbal medication & 2 \\
\hline No & 13 \\
\hline \multicolumn{2}{|l|}{ Need for assistance during bowel management } \\
\hline Yes & $41(78.8 \%)$ \\
\hline No & $11(21.2 \%)$ \\
\hline \multicolumn{2}{|c|}{ Self-reported impact on quality of life caused by neurogenic bowel dysfunction } \\
\hline No problem & $0(0 \%)$ \\
\hline Mild problem & $4(7.7 \%)$ \\
\hline Moderate problem & $13(25.0 \%)$ \\
\hline Severe problem & $22(42.3 \%)$ \\
\hline Complete problem & $13(25.0 \%)$ \\
\hline
\end{tabular}


Table 3 Comparison of the compliant group $(n=18)$ with the noncompliant group $(n=34)$

\begin{tabular}{|c|c|c|}
\hline & $\begin{array}{l}\text { Compliant } \\
\text { group } \\
(\mathrm{N}=18)\end{array}$ & $\begin{array}{c}\text { Noncompliant } \\
\text { group } \\
(\mathrm{N}=34)\end{array}$ \\
\hline Age, mean \pm s.d. (range) (years) & $\begin{array}{c}45.6 \pm 7.4 \\
(31-57)\end{array}$ & $\begin{array}{c}44.0 \pm 12.5 \\
(18-65)\end{array}$ \\
\hline Sex (male/female) & $15 / 3$ & $26 / 8$ \\
\hline Time since injury, mean \pm s.d. (range) (months) & $\begin{array}{l}98.4 \pm 121.2 \\
(8.7-487.4)\end{array}$ & $\begin{array}{l}89.9 \pm 118.7 \\
(6.0-510.6)\end{array}$ \\
\hline $\begin{array}{l}\text { Type of injury } \\
\text { (tetraplegia/paraplegia) }^{a}\end{array}$ & $6 / 12$ & $22 / 12$ \\
\hline $\begin{array}{l}\text { Cause of injury } \\
\text { (traumatic/non-traumatic) }\end{array}$ & $13 / 5$ & $28 / 6$ \\
\hline Constipation (yes/no) & $10 / 8$ & $18 / 16$ \\
\hline Incontinence (yes/no) & $5 / 13$ & $10 / 24$ \\
\hline \multicolumn{3}{|l|}{ Average time required for defecation } \\
\hline$\leqslant 10 \min$ & 0 & 0 \\
\hline $11-20 \mathrm{~min}$ & 1 & 0 \\
\hline $21-30 \mathrm{~min}$ & 0 & 2 \\
\hline $31-60 \mathrm{~min}$ & 6 & 4 \\
\hline$\geqslant 61 \mathrm{~min}$ & 11 & 28 \\
\hline \multicolumn{3}{|l|}{ Frequency of defecation } \\
\hline Three times or more per day & 0 & 1 \\
\hline Twice daily & 0 & 1 \\
\hline Once daily & 4 & 1 \\
\hline Not daily but more than twice every week & 9 & 15 \\
\hline Twice every week & 5 & 10 \\
\hline Once every week & 0 & 6 \\
\hline $\begin{array}{l}\text { Need for assistance during bowel management } \\
(y e s / n o)^{b}\end{array}$ & $11 / 7$ & $30 / 4$ \\
\hline $\begin{array}{l}\text { Need for assistance during TAI at 1-month follow- } \\
\text { up (yes/no) }{ }^{c}\end{array}$ & $12 / 6$ & $30 / 4$ \\
\hline $\begin{array}{l}\text { Practical problems related to device of TAl at 1- } \\
\text { month follow-up (yes/no) }\end{array}$ & $9 / 9$ & $21 / 13$ \\
\hline $\begin{array}{l}\text { Adverse effect related to TAI at } 1 \text {-month follow-up } \\
\text { (yes/no) }\end{array}$ & $6 / 12$ & $10 / 24$ \\
\hline
\end{tabular}

particular SCIPs had refused treatment by colostomy. ${ }^{14}$ Only one continued to use TAI and this individual showed a decreased defecation time after 6 months (61-90 min).

\section{Reasons for withdrawal}

Withdrawal rate was highest during the first month as was noticed in previous studies. ${ }^{2}$ Practical problems, time consumption and adverse effects as reasons for withdrawal were especially found in early stages (Figure 1). ${ }^{6}$ When comparing the 34 patients who dropped out, 10 because of not being effective and 24 for other reasons, there was no significant difference between tetraplegia and paraplegia. Of the 10 patients who found the procedure ineffective, 7 (7 out of $22,31 \%$ ) were tetraplegic and 3 ( 3 out of $12,25 \%)$ were paraplegic. Although the percentage of tetraplegia was higher, there was no statistically significant difference.
Table 4 Details of TAI outcomes for the compliant group at 6 months after entry into the study $(n=18)$

\begin{tabular}{|c|c|}
\hline & $\begin{array}{l}\text { Number }(\%) \text { of } \\
\text { patients }\end{array}$ \\
\hline Satisfaction of TAI, mean \pm s.d. & $8.33 \pm 1.37$ \\
\hline Impact of TAI on quality of life, mean \pm s.d. & $8.44 \pm 1.34$ \\
\hline Volume of water used for TAI, mean \pm s.d. $(\mathrm{ml})$ & $788.89 \pm 152.97$ \\
\hline \multicolumn{2}{|l|}{ Frequency of TAI } \\
\hline Once daily & $2(11.1 \%)$ \\
\hline Every other day & $3(16.7 \%)$ \\
\hline Twice every week & $13(72.2 \%)$ \\
\hline \multicolumn{2}{|l|}{ Other methods combined with TAI } \\
\hline Yes & $6(33.3 \%)$ \\
\hline Digital anorectal stimulation & 2 \\
\hline Digital anorectal stimulation and abdominal massage & 1 \\
\hline Suppositories & 1 \\
\hline Oral laxatives & 1 \\
\hline Digital evacuation & 1 \\
\hline No & $12(66.7 \%)$ \\
\hline \multicolumn{2}{|l|}{ Need for assistance during TAl } \\
\hline Yes & $12(66.7 \%)$ \\
\hline No & $6(33.3 \%)$ \\
\hline \multicolumn{2}{|l|}{ Problems related to device of TAI } \\
\hline Yes & $10(55.6 \%)$ \\
\hline Expulsion of the rectal catheter & 9 \\
\hline $\begin{array}{l}\text { Difficulty of catheter insertion with stool present in the } \\
\text { rectum }\end{array}$ & 1 \\
\hline No & $8(44.4 \%)$ \\
\hline
\end{tabular}

Table 5 Effects of transanal irrigation on bowel management at 6 months after entry into the study $(n=18)$

\begin{tabular}{lcc}
\hline & At entry & At 6 months \\
\hline $\begin{array}{l}\text { Average time required for defecation } \\
\leqslant 10 \text { min }\end{array}$ & 0 & \\
$11-20$ min & 1 & 2 \\
$21-30$ min & 0 & 5 \\
$31-60$ min & 6 & 9 \\
$\geqslant 61$ min & 11 & 1 \\
& & \\
Self-reported impact on quality of life caused by neurogenic bowel dysfunction \\
No problem & 0 & 2 \\
Mild problem & 2 & 6 \\
Moderate problem & 6 & 8 \\
Severe problem & 4 & 0 \\
Complete problem & 6 & \\
\hline
\end{tabular}

\section{Practical problems and adverse effects}

Of the 52 enrollees, 33 (63.5\%, tetraplegia:paraplegia $=16: 17)$ reported practical problems with the TAI procedure at 1-month after entry. The most common problem was expulsion of the rectal catheter, which occurred in 25 individuals (Figure 2). In addition, 15 participants $(28.8 \%$, tetraplegia:paraplegia $=8: 7)$ presented with adverse effects at 1 month and abdominal pain or discomfort was 


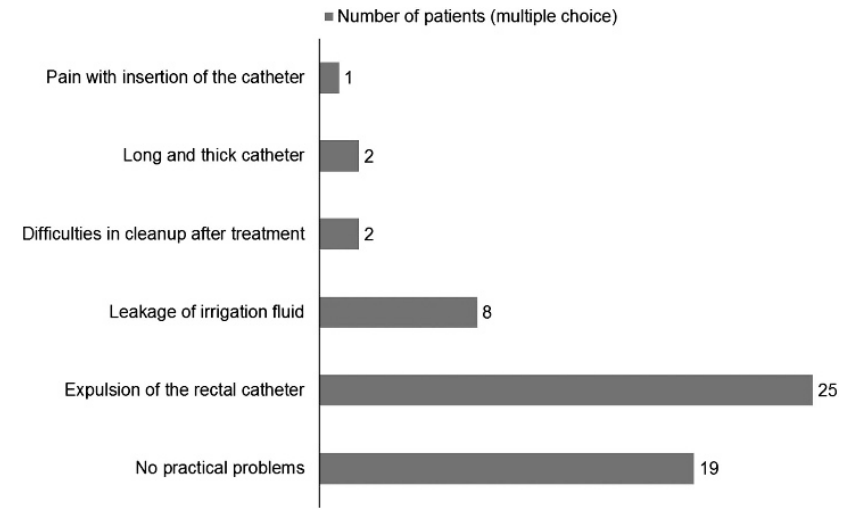

Figure 2 Practical problems with TAI $(n=52)$.

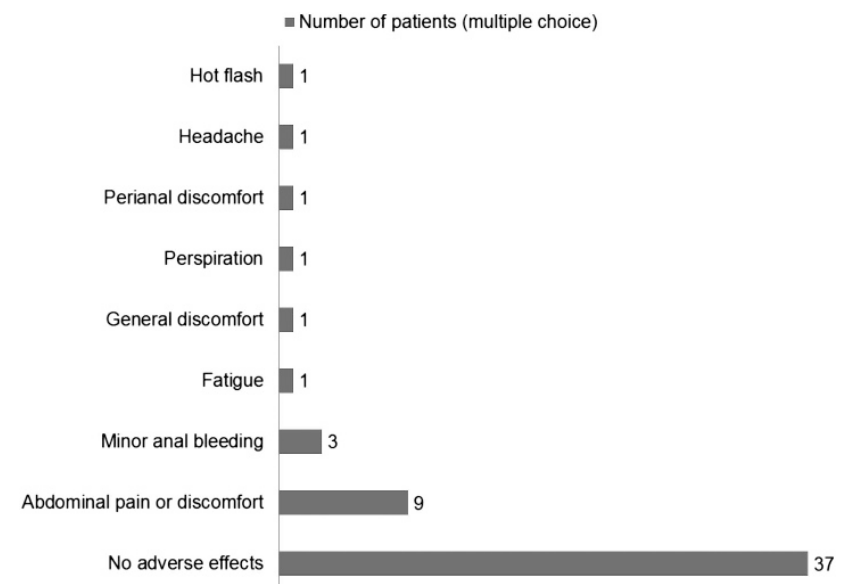

Figure 3 Adverse effects of TAI $(n=52)$.

most frequently reported (Figure 3). There was no significant difference between tetraplegia and paraplegia.

\section{DISCUSSION}

In this study, successful outcome with TAI was achieved in $34.6 \%$ of participants at 6 months. This percentage is lower than reported previously, ${ }^{1,2,4,6,8}$ although this might be due to differences in patient demographics, comorbidities and study duration. The dependency on others is an important consideration in this study, because those who did not continue with TAI were disproportionately from the tetraplegia group rather than from the paraplegia group. Noncompliant group also showed higher need for assistance during bowel management. The low success rate with TAI in this study could also be explained by the nature of the Korean health-care system. For example, TAI is not reimbursed by the Korean national health insurance program, meaning that participants had to cover all the expenses of the TAI device after the study had been completed, which could result in a lower degree of satisfaction. In addition, personal assistants are supplied for only $250 \mathrm{~h}$ per month and they are not well trained for bowel care in SCIPs in Korea. This might increase the dropout rate. In this regard, some SCIPs consider bowel dysfunction a strictly personal matter and therefore refuse outside help. ${ }^{10}$ The SCIPs with this attitude might try more not to put the pressure on their caregivers. Therefore, more national insurance support for SCIPs and targeted training in the management of SCIPs will be needed before TAI can progress into common usage.
In previous studies with the Peristeen system, poor dexterity or a dependency on others for bowel management did not restrict the use of TAI. This was because of the special features of the Peristeen system, which was designed for self-administered TAI by immobilized patients and patients with poor dexterity. ${ }^{1,6}$ However, in this study, there was a relatively high ratio of tetraplegics to paraplegics and great need for physical assistance in the noncompliant group. This appears to be related to the limited support for SCIPs from Korean government funds and also reluctance by Korean SCIPs to burden their caregivers.

At the 6-month follow-up, the compliant group showed a decreased defecation time and an increased QoL, relative to baseline, and these were in agreement with previous studies. ${ }^{1,4,6}$ Eleven SCIPs who needed physical help for bowel care before TAI showed no change after TAI, and one patient who acted independently for bowel care before study entry required physical assistance with TAI. In a previous study, 15 of 36 patients using TAI reported a decrease in the need for physical help, whereas there was no detectable change for 21 individuals. ${ }^{6}$ Given that the TAI device was designed for self-use, it is difficult to understand why many SCIPs do not use it independently at present.

Of the 18 patients who continued to use TAI for at least 6 months, one spent 2 days per week and up to $12 \mathrm{~h}$ per day on bowel care. His refusal of a colostomy is consistent with the fact that Koreans tend to avoid colostomy unless it is inevitable. ${ }^{9}$ The refusal to undergo colostomy for SCI-induced neurogenic bowel disease was also reported in a previous Korean study. ${ }^{10}$ Although a colostomy is a well-accepted treatment for $\mathrm{NBD},{ }^{14,15}$ it appears to be less well accepted in Korean culture. ${ }^{11}$ As TAI has been suggested for disordered defecation before any irreversible surgery, ${ }^{16}$ it could function in this way before conducting colostomy.

Practical problems with TAI were reported in $63.5 \%$ of participants and for $48.1 \%$ the problem was expulsion of the rectal catheter. Previous reports have described expulsion of the rectal catheter during irrigation in approximately $25 \%$ of patients. ${ }^{1,6}$ Catheter expulsion is to be expected in patients with supraconal SCI, as they often have reduced rectal compliance and hyperreactivity to distension. ${ }^{17}$ Our study showed a relatively high overall rate (48.1\%) of catheter expulsion; however, only $12.5 \%$ of the 34 persons in the dropout group chose this problem as the cause of discontinuance. From the 52 participants, 15 (28.8\%) presented with an adverse effect, and this was a lower rate than in previous studies. ${ }^{2,6}$ In all studies, abdominal pain or discomfort was the most commonly reported problem. However, neither adverse effects nor practical problems were the main cause of study dropout. Indeed, only $14.5 \%$ of our dropouts stopped because of an adverse effect, and this is similar to another study where only $12 \%$ of patients dropped out because of a side effect. ${ }^{2}$ In that study, it was suggested that because of the major increase in QoL measures, patients will ignore side effects when colorectal function is improved, and this might also explain our data.

Finally, regular home education by specialized medical personnel might improve the success rate, although this was not studied here. More active intervention may be needed for SCIPs and their caregivers who are accustomed to current methods for defecation. The current need for physical assistance and practical problem during TAI might be ameliorated by such interventions.

\section{CONCLUSION}

In this study, 18 of 52 (34.6\%) Korean participants continued to use the TAI system at 6 months after entry, which was a lower level of 
compliance than observed in some European countries. The dependency on others is an important factor related to compliance in this study. Practical problems with the equipment or adverse effects of TAI were not responsible for low compliance. We conclude that TAI could be an efficient management tool for NBD of SCIPs in Korea, given adequate assistance and instruction.

\section{DATA ARCHIVING}

There were no data to deposit.

\section{CONFLICT OF INTEREST}

The authors declare no conflict of interest.

\section{ACKNOWLEDGEMENTS}

This study was partly supported by Coloplast Korea.

1 Christensen P, Bazzocchi G, Coggrave M, Abel R, Hulting C, Krogh K et al. Outcome of transanal irrigation for bowel dysfunction in patients with spinal cord injury. J Spinal Cord Med 2008; 31: 560-567.

2 Faaborg PM, Christensen P, Kvitsau B, Buntzen S, Laurberg S, Krogh K. Long-term outcome and safety of transanal colonic irrigation for neurogenic bowel dysfunction. Spinal cord 2009; 47: 545-549.

3 Emmanuel A. Review of the efficacy and safety of transanal irrigation for neurogenic bowel dysfunction. Spinal cord 2010; 48: 664-673.

4 Del Popolo G, Mosiello G, Pilati C, Lamartina M, Battaglino F, Buffa P et al. Treatment of neurogenic bowel dysfunction using transanal irrigation: a multicenter Italian study. Spinal cord 2008; 46: 517-522.
5 Krogh K, Nielsen J, Djurhuus JC, Mosdal C, Sabroe S, Laurberg S. Colorecta function in patients with spinal cord lesions. Dis Colon Rectum 1997; 40 1233-1239.

6 Christensen P, Bazzocchi G, Coggrave M, Abel R, Hultling C, Krogh K et al. A randomized, controlled trial of transanal irrigation versus conservative bowel management in spinal cord-injured patients. Gastroenterology 2006; 131 . 738-747.

7 Christensen P, Andreasen J, Ehlers L. Cost-effectiveness of transanal irrigation versus conservative bowel management for spinal cord injury patients. Spinal cord 2009; 47 138-143.

8 Christensen P, Krogh K, Buntzen S, Payandeh F, Laurberg S. Long-term outcome and safety of transanal irrigation for constipation and fecal incontinence. Dis Colon Rectum 2009; 52: 286-292.

9 Kim JY, Koh ES, Leigh J, Shin HI. Management of bowel dysfunction in the community after spinal cord injury: a postal survey in the Republic of Korea. Spinal cord 2012; 50: 303-308.

10 Han TR, Kim JH, Kwon BS. Chronic gastrointestinal problems and bowel dysfunction in patients with spinal cord injury. Spinal cord 1998; 36: 485-490.

11 Holzer B, Matzel K, Schiedeck T, Christiansen J, Christensen P, Rius J et al. Do geographic and educational factors influence the quality of life in rectal cancer patients with a permanent colostomy? Dis Colon Rectum 2005; 48: 2209-2216.

12 Krogh K, Perkash I, Stiens SA, Biering-Sorensen F. International bowel function basic spinal cord injury data set. Spinal cord 2009; 47: 230-234.

13 World Health Organization. International Classification of Functioning, Disability and Health (ICF), 2001, Committee for Korean Translation and Publishing of ICF (Trans). Ministry of Health and Welfare: Seoul: Korea, 2004, pp. 129-130.

14 DeLisa JA, Gans BM, Walsh NE. Physical Medicine and Rehabilitation: Principles and Practice, 4th edn, vol. II. Lippincott Williams \& Wilkins: Philadelphia, 2010, pp 1649

15 Branagan G, Tromans A, Finnis D. Effect of stoma formation on bowel care and quality of life in patients with spinal cord injury. Spinal cord 2003; 41: 680-683.

16 Christensen P, Krogh K. Transanal irrigation for disordered defecation: a systematic review. Scand J Gastroenterol 2010; 45: 517-527.

17 Krogh K, Mosdal C, Gregersen H, Laurberg S. Rectal wall properties in patients with acute and chronic spinal cord lesions. Dis Colon Rectum 2002; 45: 641-649. 